\title{
Rheological Investigation of the Influence of Short Chain Branching and Mw of LDPE on the Melt Miscibility of LDPE/PP Blends
}

\author{
M.A. Suleiman ${ }^{1}$, I.A. Hussein ${ }^{* 1}$ and M.C. Williams ${ }^{2}$ \\ ${ }^{I}$ Department of Chemical Engineering, King Fahd University of Petroleum \& Minerals, P.O. Box 1399, Dhahran \\ 31261, Saudi Arabia; ${ }^{2}$ Department of Chemical \& Materials Engineering, University of Alberta, Edmonton, Canada \\ T6G 2 G6
}

\begin{abstract}
The influences of short chain branching (SCB) and molecular weight (Mw) of low density polyethylene (LDPE) on its melt miscibility with polypropylene (PP) were investigated by rheological techniques. Rheological measurement and different data-treatment techniques as well as rheological models suggest that blends of PP with LDPE of high SCB $\left(22 \mathrm{CH}_{3} / 1000 \mathrm{C}\right)$ are miscible at all compositions. However, blends of LDPE with low SCB $\left(8.3 \mathrm{CH}_{3} / 1000 \mathrm{C}\right)$ are immiscible in the LDPE-rich and miscible in PP-rich regimes. It was suggested that matching the conformations of PP and LDPE and matching the Mw of LDPE and PP is a key to the melt miscibility of PP/LDPE blends. The experimental results are in agreement with theoretical predictions on the miscibility of polyolefin blends.
\end{abstract}

Keywords: Polypropylene, low density polyethylene, miscibility, rheology, branching.

\section{INTRODUCTION}

Previous investigations have shown that blending of two or more polymers rather than synthesizing new materials is one of the most efficient ways to satisfy new requirements for improved material properties [1,2]. Blends of polypropylene (PP) and polyethylene (PE) have become a subject of great economic and research interest because of the need to improve the processing and properties of PP as an engineering plastic due to its relatively low impact strength especially at low temperature and poor environmental stress cracking resistance [3-5]. However, the miscibility of PP/PE blends is still a research subject even though PP and PE have many similarities in properties [6,7].

Different commercial grades of PE, such as low density polyethylene (LDPE), high density polyethylene (HDPE), linear low density polyethylene (LLDPE), ultra high molecular weight polyethylene (UHMWPE), very low density polyethylene (VLDPE) and ultra low density polyethylene (ULDPE) are available and have been used to form physical blends with PP. Blends of PP with LLDPE, VLDPE, and ULDPE have been reported to be miscible, partially miscible or immiscible [8-10]. However, PP/LDPE blends have been reported to give a better balance between toughness improvements and stiffness reduction because LDPE is characterized by good toughness, flexibility and excellent processability [11-14].

The properties and phase structures of PP/LDPE blends in isotropic and oriented states were investigated [15] by the methods of differential scanning calorimetry (DSC) and polarization infra red spectroscopy and it was found that the presence of LDPE in the blend increases the degree of PP orientation and the mechanical strength of the blend samples.

*Address correspondence to this author at the Department of Chemical Engineering, King Fahd University of Petroleum \& Minerals, P.O. Box 1399, Dhahran 31261, Saudi Arabia; Tel: 966-3-860-2235-4234; Fax: +9663-860 4234; E-mail: ihussein@kfupm.edu.sa
This shows that LDPE acts as a structure-modifying agent, while PP plays the role of reinforcing filler. The miscibility of PP/LDPE blends was investigated by different techniques and the popularly held opinion is that these blends are generally immiscible and form blends with low interfacial adhesion between the polymer phases although some investigations have reported partial miscibility [2, 16-19]. The observed disagreement in the miscibility of PP/PE blends is likely due to the details of the structure and type of PE, a subject that is not discussed in the literature.

In a study by Avalos et al. [11], the effects of addition of small amount of LDPE on the crystallization kinetics of PP using DSC technique was investigated. The thermodynamics of the studied systems showed that the chain folding energy for the PP crystallization increased at LDPE concentration greater than $10 \%$ because of the hindrance created by the LDPE aggregates present in the blend. This was interpreted as partial miscibility of the blend in the melt [20].

It is evident that even though blends of PP/LDPE are generally believed to be immiscible some studies have shown that some level of miscibility of the blend is obtainable at some concentrations $[2,16]$. No systematic study was performed to understand why some blends are miscible while others are not. In addition, no study to our knowledge has investigated how the individual polymer characteristics affect the melt miscibility of the blend. Thus, the aim of this study is to investigate the influence of short chain branching (SCB) and molecular weight (Mw) of LDPE on its miscibility with PP blends. Rheometry will be used to determine the miscibility of the blends since rheological properties of polymers are sensitive to both molecular structure and phase behavior.

\section{EXPERIMENTAL}

\section{Materials}

Three commercial samples of LDPE and one PP were used in this study. The LDPEs were designated by LDPE1, 
Table 1. Characterization of Resins

\begin{tabular}{|c|c|c|c|c|c|}
\hline Resin & Density $\left(\mathbf{g} / \mathbf{c m}^{\mathbf{3}}\right)$ & MFI (g/10min) & $\mathbf{M}_{\mathbf{w}}(\mathbf{k g} / \mathbf{m o l})$ & MWD & SCB $(\mathbf{C H} / \mathbf{1 0 0 0 C})$ \\
\hline \hline PP & 0.9000 & 18 & 211 & 5.86 & - \\
LDPE1 & 0.9230 & 1.2 & 100 & 4.14 & 8.3 \\
LDPE2 & 0.9230 & 4.0 & 84 & 4.16 & 9 \\
LDPE3 & 0.9190 & 0.75 & 107 & 6.50 & 22 \\
\hline
\end{tabular}

LDPE2 and LDPE3. LDPE1 and LDPE2 were obtained from ExxonMobil Chemicals (Belgium) while LDPE3 and PP were obtained from Nova chemicals (Canada) and SABIC (Saudi Arabia), respectively. The characterization data for the resins are presented in Table $\mathbf{1}$. The number average and weight average molecular weights of the resins were determined by gel permeation chromatography (GPC) in a WATERS GPC2000 instrument and ${ }^{13} \mathrm{C}$ NMR was used for the determination of SCB. These tests were performed at the Polymer Research laboratory and Chemistry department of King Fahd University of Petroleum \& Minerals, Saudi Arabia. Details of GPC and NMR characterization are given elsewhere [21].

The effect of Mw of LDPE on the miscibility of PP/LDPE blends was investigated by comparing PP/LDPE1 and PP/LDPE2 blends. LDPE1 and LDPE2 were selected in such a way that $\mathrm{Mw}$ of the LDPE was the only molecular parameter with appreciable difference. On the other hand, LDPE1 and LDPE3 blends were chosen for the investigation of the effect of SCB of LDPE on the blend miscibility. This is due to the significant difference in SCB of LDPE1 and LDPE3. In fact, the densities of these two LDPE resins represent the upper and lower limits of the density of commercial LDPE. The density is inversely related to the level of SCB. The rheology of both LDPE1 and LDPE3 is similar and shows no shear thinning behavior at low shear rates. This suggests that the levels of long chain branching of theses LDPEs are similar. Therefore, the SCB is the primary molecular variable between LDPE1 and LDPE3. Blends of $10,30,50,70,80$ and $90 \%$ by weight $\mathrm{PP}$ and the pure resins were tested in this study.

\section{Melt Blending and Specimen Preparation}

Blends of PP/LDPE1, PP/LDPE2, and PP/LDPE3 at the composition of interest were prepared in a Haake Polydrive melt blender at $50 \mathrm{rpm}$ and $190^{\circ} \mathrm{C}$ for 10 minutes. A separate investigation on the thermo-mechanical degradation of PP and LDPE based on the blending conditions was performed and it was observed that the dynamic viscosity and storage modulus of the conditioned sample were lower than those of the as-received sample. After a series of tests, it was established that the addition of $3000 \mathrm{ppm}$ of anti-oxidant (AO) to all resins was adequate to avoid degradation during melt blending [22]. The $\mathrm{AO}$ is a $50 / 50$ blend of a primary $\mathrm{AO}$ (Irganox 1010) and a secondary AO (Irgafos 168) obtained from Ciba-Geigy Specialty Chemicals. Fig. (1a, b) shows the rheology of as-received and conditioned LDPE1 and PP, respectively. Agreement of the data for the as-received samples with samples conditioned with extra AO shows that the amount of extra AO was able to prevent degradation during melt blending.
In all cases, samples obtained from the blender were subjected to a controlled thermomechanical history in a Carver press in order to prepare flat circular discs $(25 \mathrm{~mm}$ diameter, $2 \mathrm{~mm}$ thick) for insertion between the rheometer platens. The Carver press was operated at $190^{\circ} \mathrm{C}$. The sample was allowed to melt for 8 minutes, and load was increased from 1 to 7 tons at a step of 2 tons and a hold time of 1 minute. At the end of this molding process samples were water-cooled for 10 minutes.

\section{Rheological Measurements}

The dynamic frequency sweep and dynamic strain sweep measurements for the samples were performed in ARES rheometer. This is a constant strain rheometer equipped with a heavy transducer (range 2-2000 $\mathrm{g}$ for normal force; 2-2000 $\mathrm{g}-\mathrm{cm}$ for torque). All tests were carried out at $200^{\circ} \mathrm{C}$ using a cone and plate set; cone angle is $0.1 \mathrm{rad}$ and platen diameter is $25 \mathrm{~mm}$. With the sample in position, the oven was closed and the polymer heated to $200^{\circ} \mathrm{C}$ for about 3 minutes, thereafter the gap between the cone and plate platen was adjusted to $0.048 \mathrm{~mm}$ by lowering the upper platen force transducer assembly at a constant load of $500 \mathrm{~g}$. The melt that extruded beyond the platen rim by this procedure was cleaned off. Strain sweep measurements were performed first and a strain in the linear viscoelastic range (strain amplitude, $\gamma_{\mathrm{o}}$ of $15 \%$ ) was used for all tests. In all the experiments, nitrogen gas was continuously used for heating the samples during testing to avoid oxidative degradation during testing.

A holding period of 2-3 minutes was allowed before beginning measurements when the temperature reached steady state $\left(\mathrm{T}=200 \pm 0.01^{\circ} \mathrm{C}\right)$. All experiments were performed in a descending-frequency order $\left(\omega=10^{2}\right.$ to $\left.10^{-2} \mathrm{rad} / \mathrm{s}\right)$. Some tests were terminated before the final frequency was reached when the torque signal approaches the sensitivity limit of the transducer. The reason is that collection of data at low frequency takes longer time and the data would not be useful if they fall below the lower torque limit of the rheometer.

\section{RESULTS AND DISCUSSION}

\section{Influence of SCB}

The results of the dynamic shear viscosity $\left(\eta^{\prime}\right)$ and storage (elastic) modulus $\left(\mathrm{G}^{\prime}\right)$ for all blends of LDPE1 (SCB = $8.3 \mathrm{CH}_{3} / 1000 \mathrm{C}$ ) with PP are shown in Figs. (2a) and (2b), respectively. Similarly, plots of $\eta^{\prime}(\omega)$ and $G^{\prime}(\omega)$ for blends of PP/LDPE3 ( $\mathrm{SCB}=22 \mathrm{CH}_{3} / 1000 \mathrm{C}$ ) are given in Figs. (3a) and (3b), respectively. Generally, the $\eta^{\prime}(\omega)$ and $G^{\prime}(\omega)$ plots for both blend systems especially in the PP-rich region follow similar patterns, with the values of $\eta^{\prime}$ and $G^{\prime}$ for the blends bounded by the pure resins. 

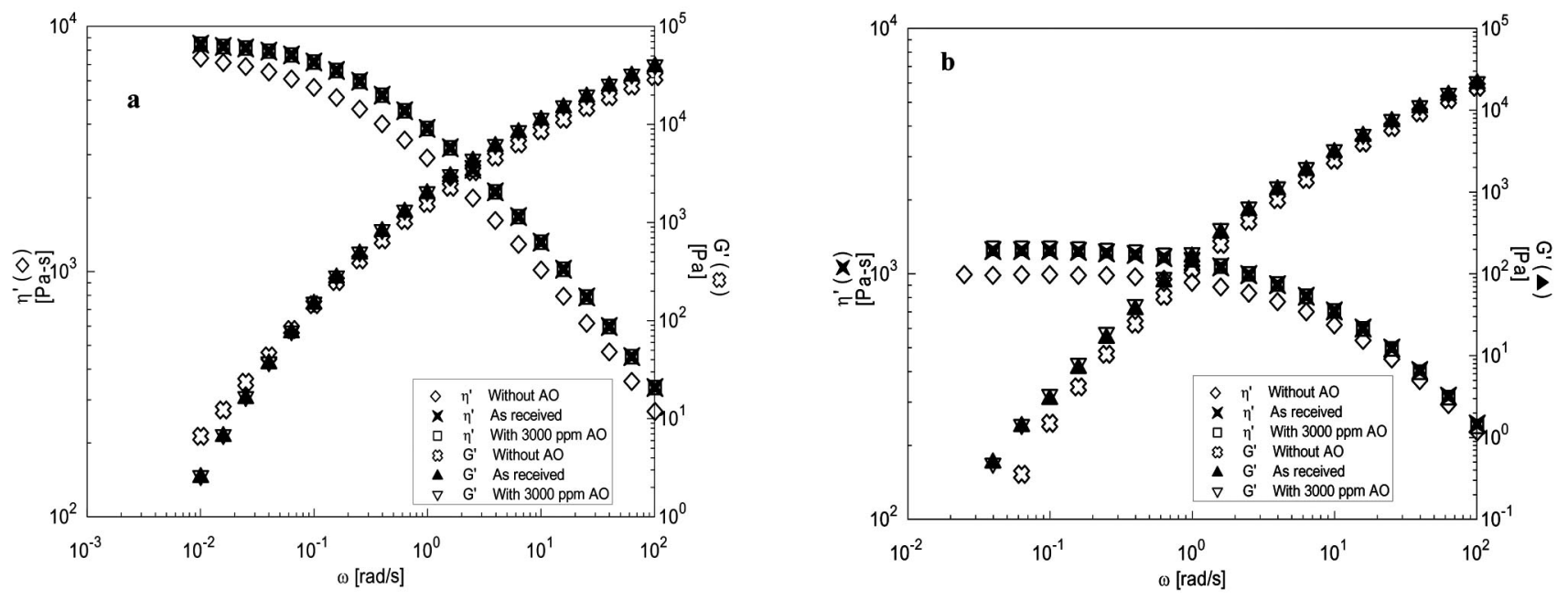

Fig. (1). Comparison of the rheology of as-received and conditioned pure resins (a) LDPE; (b) PP.

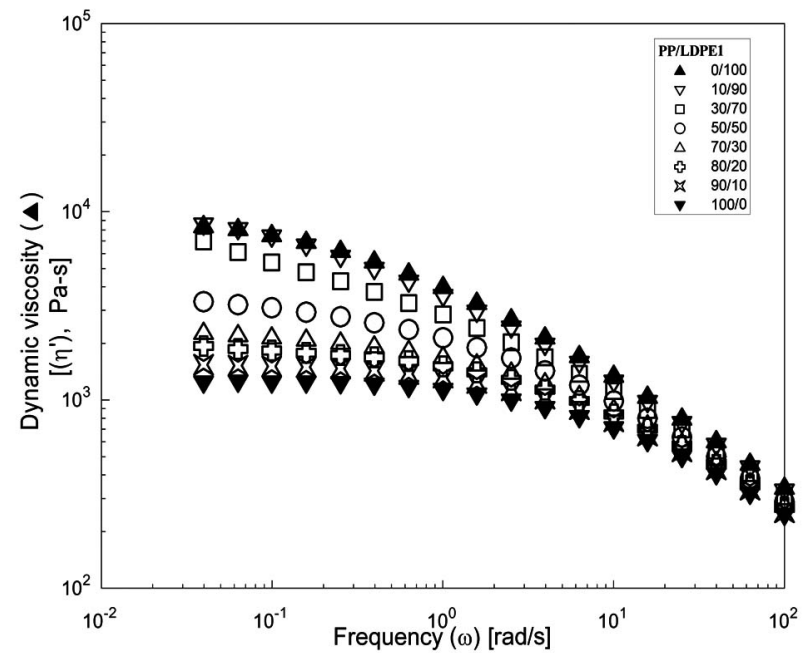

(a)

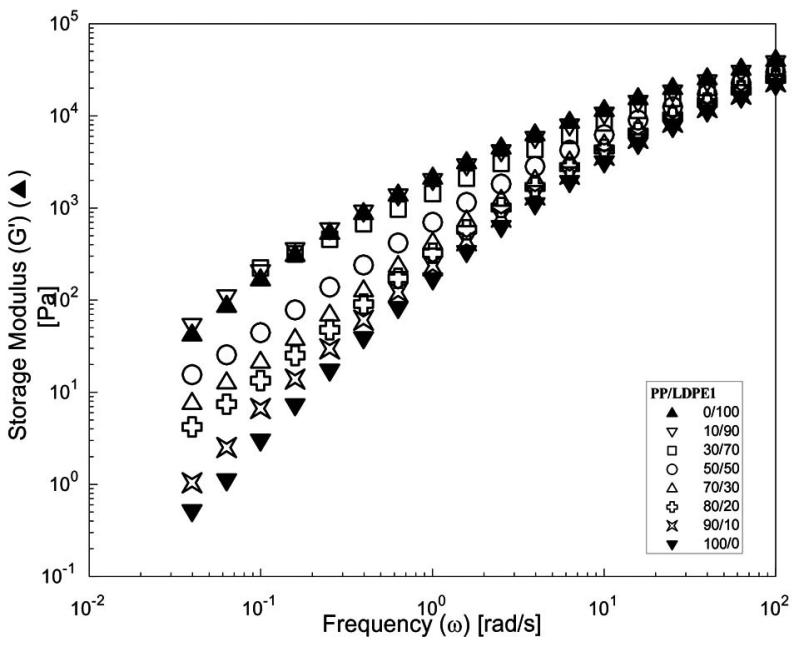

(b)

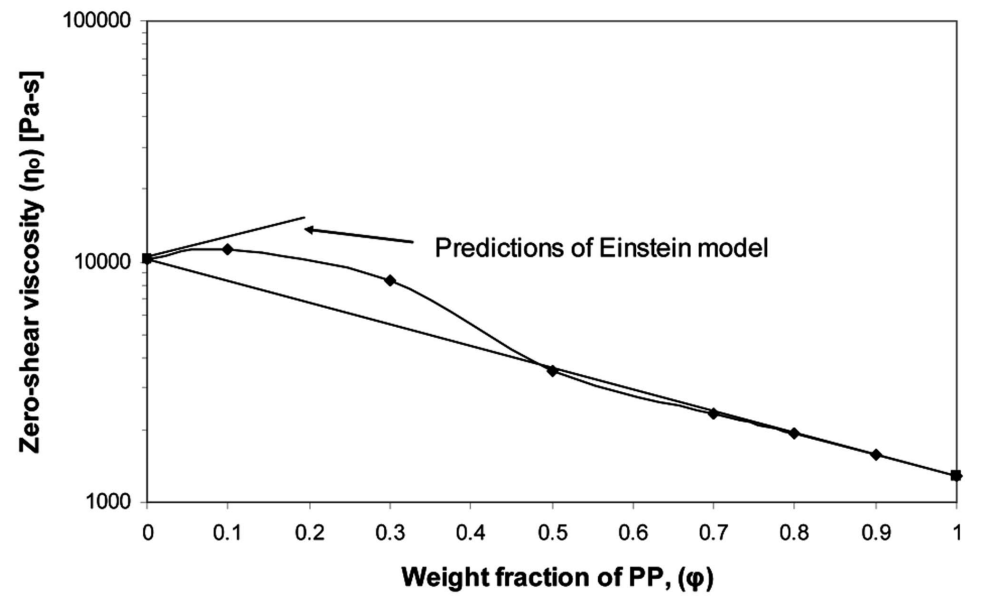

(c)

Fig. (2). (a): Dynamic viscosities $\left(\eta^{\prime}\right)$ of PP/LDPE1 blends as a function of frequency $(\omega)\left(\mathrm{T}_{\text {blend }}=190{ }^{\circ} \mathrm{C}, \mathrm{T}_{\text {test }}=200{ }^{\circ} \mathrm{C}\right)$.

(b): Storage moduli $\left(\mathrm{G}^{\prime}\right)$ of PP/LDPE1 blends as a function of frequency $(\omega)\left(\mathrm{T}_{\text {blend }}=190{ }^{\circ} \mathrm{C}, \mathrm{T}_{\text {test }}=200{ }^{\circ} \mathrm{C}\right)$.

(c): $\eta_{\mathrm{o}}(\phi)$ for blends of PP with LDPE1 $\left(\mathrm{T}_{\text {cond }}=190^{\circ} \mathrm{C}, \mathrm{T}_{\text {test }}=200^{\circ} \mathrm{C}, \gamma_{\mathrm{o}}=15 \%, \omega=0.1 \mathrm{rad} / \mathrm{s}\right)$. 


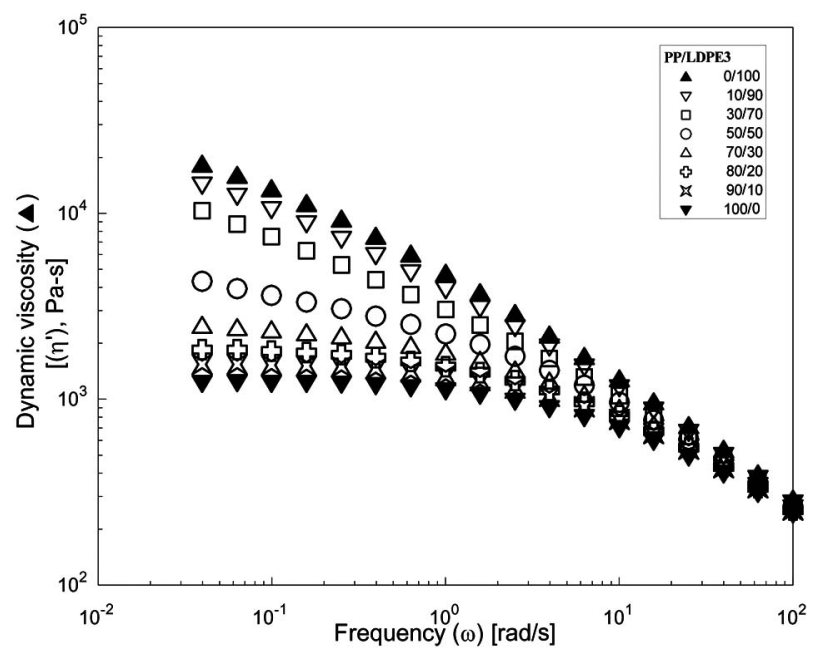

(a)

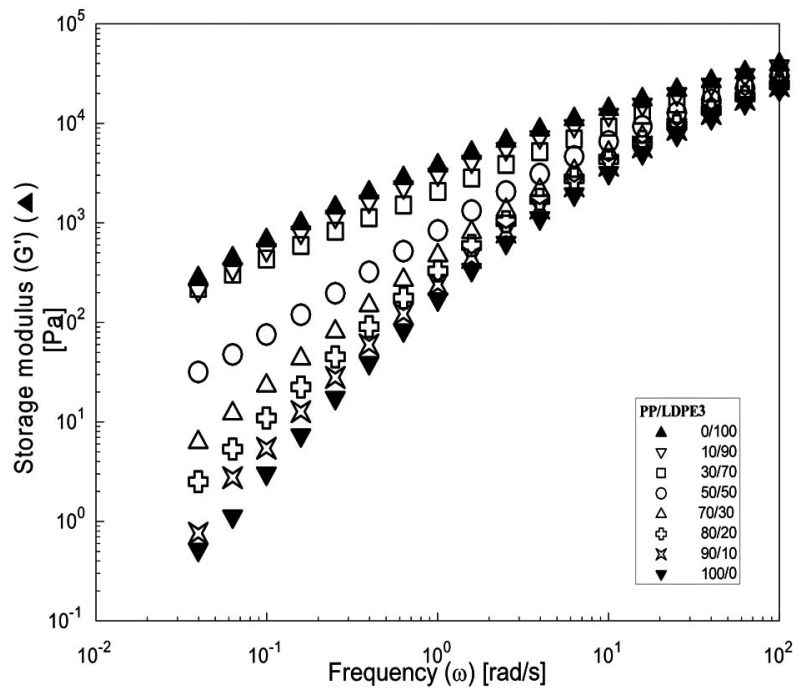

(b)

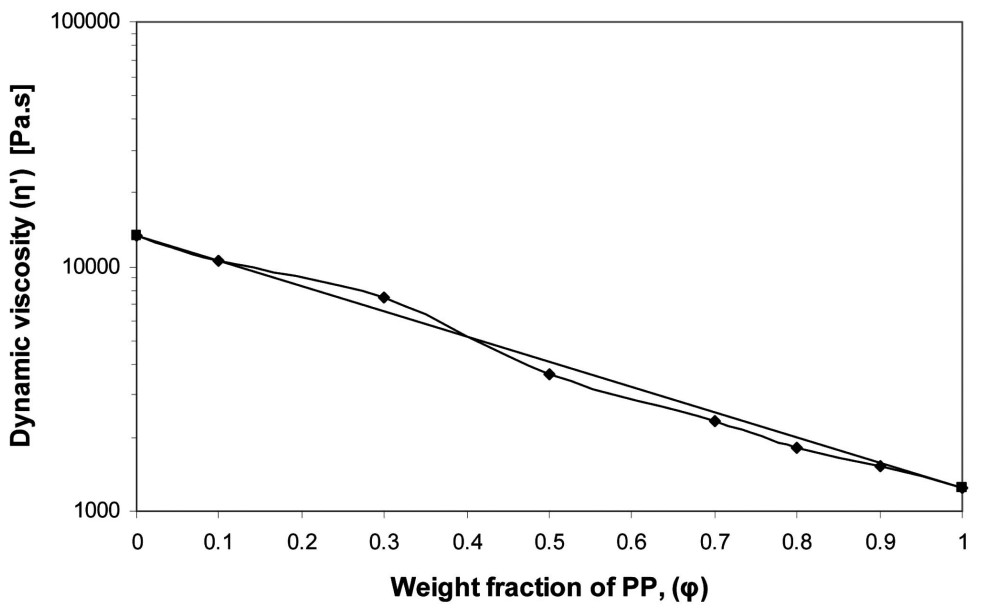

(c)

Fig. (3). (a): Dynamic viscosities ( $\left.\eta^{\prime}\right)$ of PP/LDPE3 blends as a function of frequency $(\omega)\left(\mathrm{T}_{\text {blend }}=190{ }^{\circ} \mathrm{C}, \mathrm{T}_{\text {test }}=200{ }^{\circ} \mathrm{C}\right)$.

(b): Storage moduli $\left(\mathrm{G}^{\prime}\right)$ of PP/LDPE3 blends as a function of frequency $(\omega)\left(\mathrm{T}_{\text {blend }}=190{ }^{\circ} \mathrm{C}, \mathrm{T}_{\text {test }}=200{ }^{\circ} \mathrm{C}\right)$.

(c): $\eta^{\prime}(\phi)$ for blends of PP with LDPE3 $\left(\mathrm{T}_{\text {cond }}=190^{\circ} \mathrm{C}, \mathrm{T}_{\text {test }}=200^{\circ} \mathrm{C}, \gamma_{\mathrm{o}}=15 \%, \omega=0.1 \mathrm{rad} / \mathrm{s}\right)$.

Since low- $\omega$ data is particularly sensitive to changes in morphology, it will therefore be used for the interpretations of blend miscibility [23]. In Fig. (2a), the $\eta^{\prime}(\omega)$ data for pure LDPE1 and the 10\% PP/LDPE blend appear to be equal at low frequency. This shows that the addition of small amount of the less viscous component (PP) to the more viscous component (LDPE1) did not alter the viscosity of LDPE1 at low frequency. However, in Fig. (2b), the same (10\%) blend composition shows $G^{\prime}(\omega)$ data that is slightly higher than that of the pure LDPE1. The enhancements in $G^{\prime}$ and $\eta^{\prime}$ for $\mathrm{PP} / \mathrm{PE}$ blends have been reported and this phenomena is associated with the immiscibility of blends [13, 21, 23-25]. Therefore, the increase in $G^{\prime}$ and $\eta^{\prime}$ for this blend suggests the immiscibility of LDPE1 (low SCB) blends with PP in the composition range of LDPE1-rich blends.

In order to examine the miscibility/immiscibility of these blend systems, the zero shear viscosity $\left(\eta_{\mathrm{o}}\right)$ and $\eta^{\prime}(\omega)$ at low frequency were used. The $\eta_{\mathrm{o}}$ was used for blend systems that formed Newtonian plateau at low frequency, in this case PP/LDPE1 blends and the $\eta^{\prime}(\omega)$ at low frequency was used for the PP/LDPE3 blend systems. $\eta_{\mathrm{o}}$ data were obtained by fitting the experimental $\eta^{\prime}(\omega)$ data in Fig. (2a) to the Cross model (because it gave a reasonably good fit to the viscosity data with a correlation coefficient in the range of 0.9984 $1.0000)$ with the aid of the ARES Orchestrator software and presented in Fig. (2c). The results in Fig. (2c) show two distinct patterns for blends of PP with LDPE1 (low SCB): a positive deviation behavior (PDB) from log additivity rule in the LDPE1-rich region which is indicative of emulsion morphology and suggests the immiscibility of LDPE1-rich blends supporting earlier observations; miscibility of the blends in the PP-rich region because the data follow the log additivity rule $[13,21,23,24]$. Also, the experimental data of the $10 \%$ PP/LDPE1 blend closely agree with the predictions of Einstein model for dilute emulsions of Newtonian fluids [21]. This provides additional support for the immiscibility of LDPE1-rich blends.

Data for $\eta^{\prime}$ against composition, $\phi,\left(\eta^{\prime}(\phi)\right)$ at low- $\omega$ $(\omega=0.1 \mathrm{rad} / \mathrm{s})$ were extracted from Fig. (3a), and plotted in Fig. (3c). This result suggests the partial miscibility of 
LDPE3 blends with PP at all compositions. This conclusion can also be inferred from Fig. (3a) which shows a proportional increase in $\eta^{\prime}$ when the more viscous component LDPE3 is added to PP. Similarly, the same observation can be seen in the $\mathrm{G}^{\prime}$ data displayed in Fig. (3b).

Since miscibility/immiscibility has been inferred on the basis of $\eta_{\mathrm{o}}$ and low- $\omega$ data, results in Fig. (2c) show that a $10 \%$ blend of PP with LDPE1 ( $\mathrm{SCB}=8.3 \mathrm{CH}_{3} / 1000 \mathrm{C}$ ) is immiscible where as PP/LDPE3 blend $\left(\mathrm{SCB}=22 \mathrm{CH}_{3} / 1000\right.$ C) at the same composition is suggested to be miscible (Fig. (3c)). This shows that the SCB of LDPE has influenced the melt miscibility of PP/LDPE blends in the LDPE-rich region. However, in PP-rich region, both blend systems exhibit a high degree of miscibility as indicated in Figs. (2c) and (3c) thus suggesting that $\mathrm{SCB}$ does not play a significant role as far as miscibility is concerned in this composition range. However, it is important to note that the above observations are based on $\eta^{\prime}$ data obtained at a single $\omega$ in the low- $\omega$ range.

Furthermore, the miscibility of these blends was tested by Cole-Cole plots. This is a plot of $\eta "$ vs. $\eta$ ' over the whole $\omega$ range of the blends as well as the pure resins on a log-log scale and have been used by various groups to determine the miscibility of blends, especially PE blends [23, 26, 27]. For a miscible blend system, the Cole-Cole plot is expected to exhibit a concave-down plots that follow the blend composition [28]. Figs. (4 and 5) show the Cole-Cole plots for blends of PP with LDPE1 and LDPE3, respectively. Both blend systems show a distinct concave-down pattern in the PP-rich suggesting the miscibility of the blends at these compositions, supporting the earlier conclusion from the $\eta^{\prime}(\phi)$ and $\eta^{\prime}(\omega)$ data.

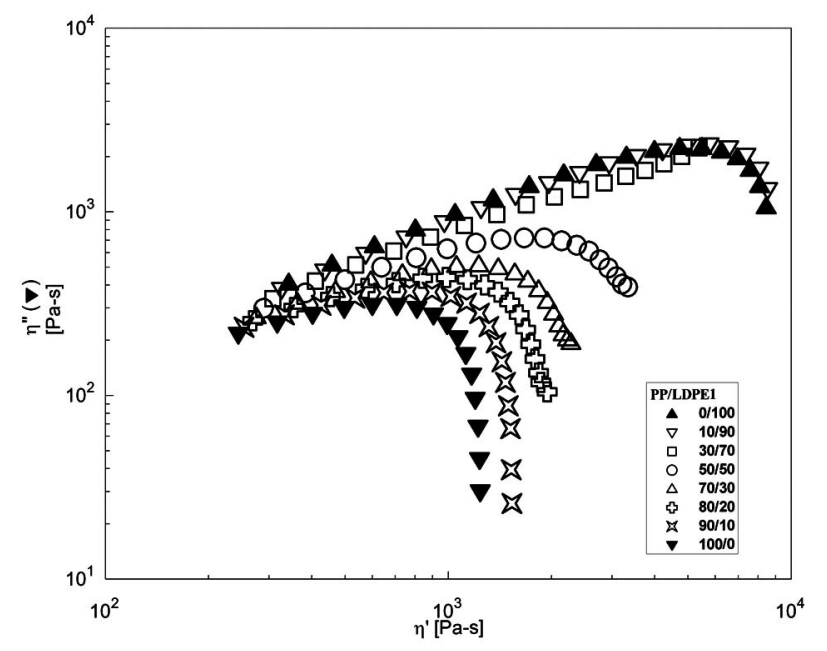

Fig. (4). Cole-Cole plots for PP/LDPE1 blends.

As an attempt to explain the above findings, we suggest that it is likely that the high SCB content LDPE3 forms a more random conformation in the melt that is similar to the conformations of $\mathrm{PP}$ which has a $-\mathrm{CH}_{3}$ branch in each monomer. The pendant $\mathrm{CH}_{3}$ in $\mathrm{PP}$ tends to disturb the chain folding and thus form a more random structure. These explanations are in agreement with theoretical predictions of Fredrickson and co-workers on the thermodynamics of polyolefin blends in the melt state [29-31]. The fact that miscibil-

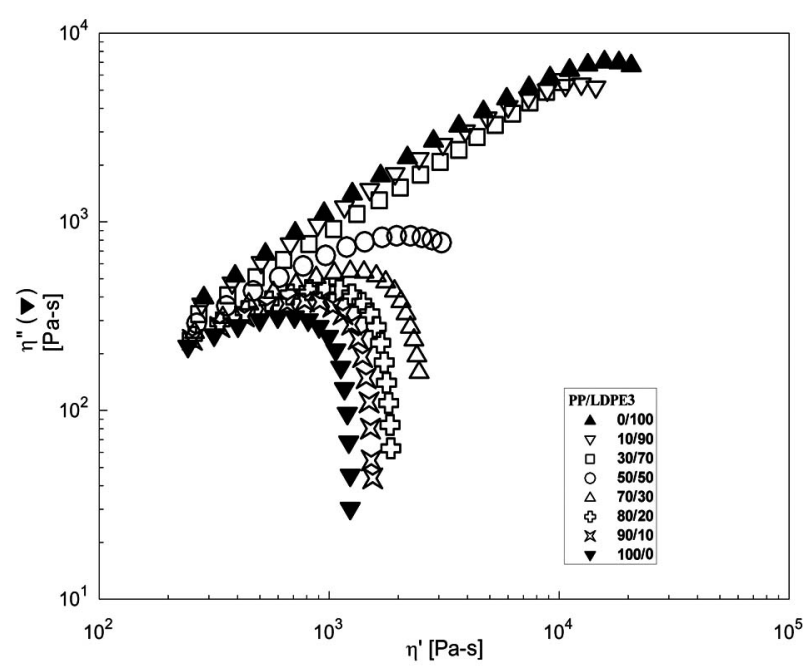

Fig. (5). Cole-Cole plots for PP/LDPE3 blends.

ity is not symmetric in composition is also manifested in the current results and predicted by these thermodynamic theories. The validity of the predictions of thermodynamic theories to PP/LDPE blends will be the subject of a future MD simulations study. Also, previous studies of Hussein and Williams groups have shown the validity of these explanations in LLDPE/LDPE and LDPE/HDPE systems in the melt state [21, 24, 32-34]. Therefore, it is suggested that the principle of similarity of conformations that is proved for PE/PE systems is likely to be generalized to PP/LDPE blends.

\section{Influence of $\mathrm{Mw}$}

In order to study the influence of Mw of LDPE on the melt miscibility of PP/LDPE blends another blend of PP with LDPE was investigated. The LDPE is denoted as LDPE2 and was chosen in such a way that it has the same density and SCB as LDPE1 (see Table 1). Melt flow index (MFI) is inversely related to Mw. Therefore Table 1 shows that MFI and GPC measurements indicate that $\mathrm{Mw}$ is the only primary varying molecular variable in this study. We understand that the difference in $\mathrm{Mw}$ in the samples used in this study is not that high. Therefore, our results and conclusions on the influence of $\mathrm{Mw}$ are limited to the range covered in the study.

Plots of $\eta^{\prime}(\omega)$ and $G^{\prime}(\omega)$ are shown in Figs. (6a) and (6b) for blends of PP with LDPE2. The plots follow the same pattern as those of PP/LDPE1 but LDPE2 blends with PP showed lower values for $\eta^{\prime}(\omega)$ and $G^{\prime}(\omega)$ as a result of the low Mw of LDPE2. In fact the data predict some role for $\mathrm{Mw}$ in the melt miscibility of these blends. In the low- $\omega$ range of the LDPE2-rich blends, the 10\% and 30\% PP blends showed a higher $\eta^{\prime}$ than that of the more viscous LDPE2. This increase in $\eta^{\prime}$ and G' of LDPE2 as a result of the addition of a low viscosity component (PP) suggests the presence of multiphase systems as discussed earlier [21].

In order to examine the miscibility/immiscibility of these blends, $\eta_{\mathrm{o}}$ data were obtained from Fig. (6a) and plotted as a function of composition as shown in Fig. (6c). All blend compositions, with the exception of the 50/50 PP/LDPE2 blend, do not follow the log additivity rule. A PDB from log additivity rule is observed for the PP-rich and LDPE2-rich 


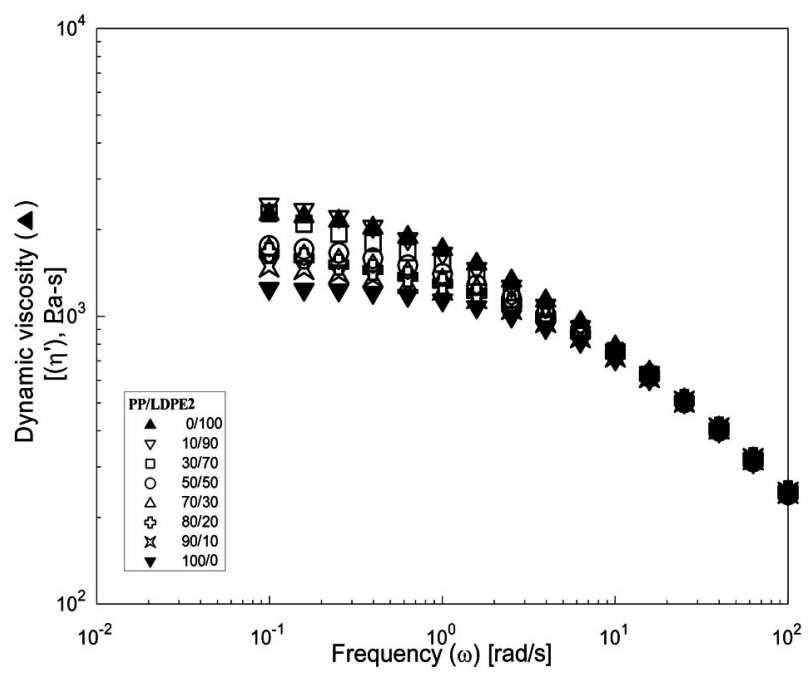

(a)

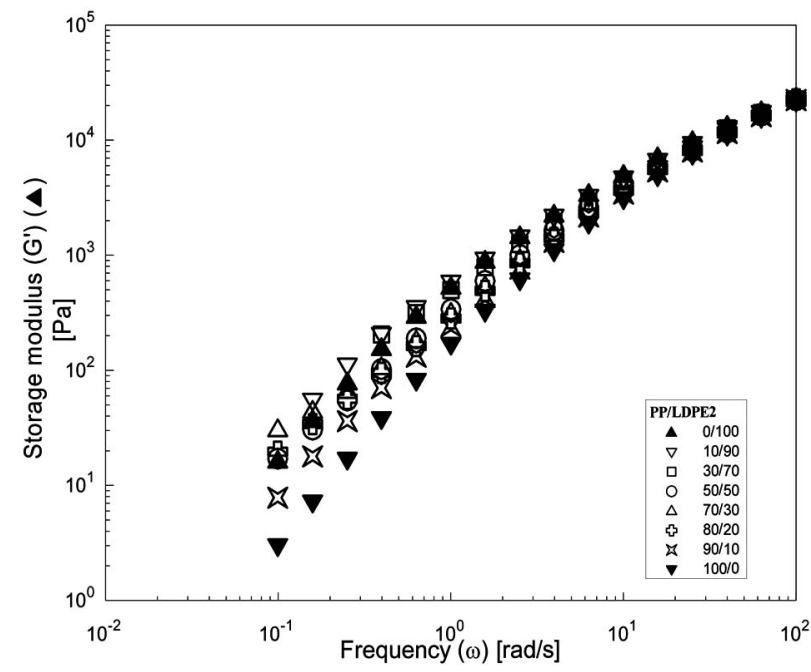

(b)

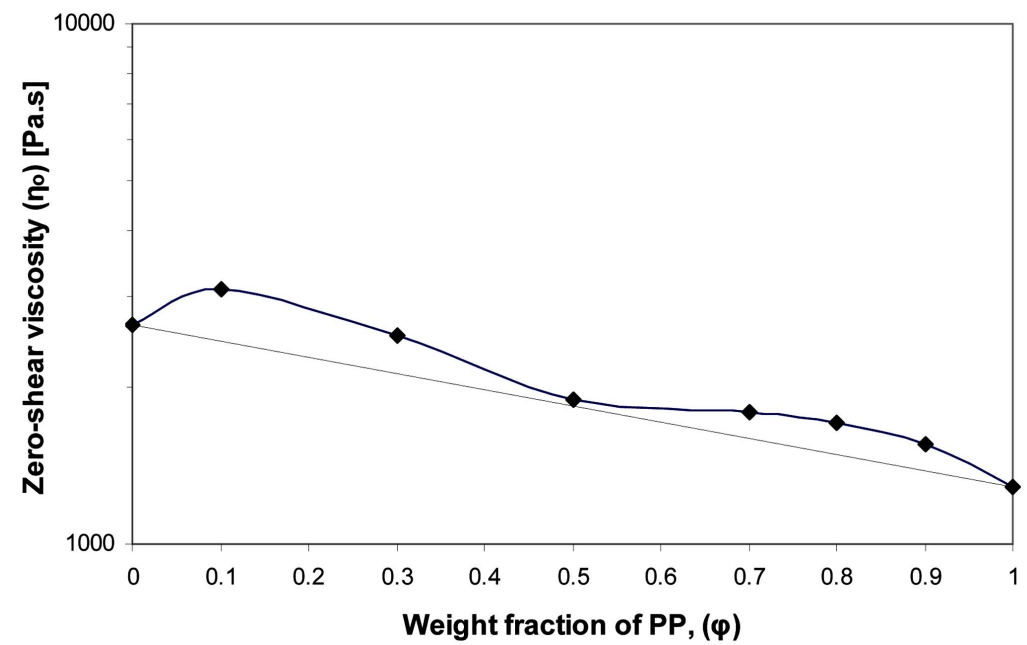

(c)

Fig. (6). (a): Dynamic viscosities $\left(\eta^{\prime}\right)$ of PP/LDPE2 blends as a function of frequency $(\omega)\left(\mathrm{T}_{\text {blend }}=190{ }^{\circ} \mathrm{C}, \mathrm{T}_{\text {test }}=200^{\circ} \mathrm{C}\right)$.

(b): Storage moduli $\left(\mathrm{G}^{\prime}\right)$ of PP/LDPE2 blends as a function of frequency $(\omega)\left(\mathrm{T}_{\text {blend }}=190{ }^{\circ} \mathrm{C}, \mathrm{T}_{\text {test }}=200{ }^{\circ} \mathrm{C}\right)$.

(c): $\eta_{\mathrm{o}}(\phi)$ for blends of PP with LDPE2 $\left(\mathrm{T}_{\text {cond }}=190^{\circ} \mathrm{C}, \mathrm{T}_{\text {test }}=200^{\circ} \mathrm{C}, \gamma_{\mathrm{o}}=15 \%, \omega=0.1 \mathrm{rad} / \mathrm{s}\right)$.

blends indicating immiscibility of these blends. This behavior could be a characteristic of emulsion morphology as discussed earlier. However, these observations are contrary to those seen in the high Mw blends (PP/LDPE1), where miscibility was suggested for blends with $50 \%, 70 \%$ and $90 \%$ PP compositions. From the foregoing it can be concluded that the high Mw PP used in this study is more compatible with the high Mw LDPE1. It is therefore likely that Mw is another parameter that can influence miscibility. Matching of molecular conformation as depicted by Bates and Fredrickson [29] is likely to be Mw dependent especially Mw is expected to influence the entropic part of the Gibbs free energy [31].

\section{CONCLUSIONS}

In conclusion, the influences of SCB and Mw of LDPE on the miscibility of PP/LDPE blends were investigated. Rheological measurement and data-treatment technique which include plots of $\eta^{\prime}(\omega), G^{\prime}(\omega), \eta^{\prime}(\phi)$, and Cole-Cole plots showed that blends of PP with LDPE of low SCB (8.3
$\mathrm{CH} 3 / 1000 \mathrm{C}$ ) have a higher degree of immiscibility especially in the LDPE-rich region than those of LDPE with high SCB (22 CH3/1000 C). Blends containing high SCB LDPE were suggested to be miscible with $\mathrm{PP}$ in the whole composition range where as blends of low SCB LDPE were found to be immiscible in the composition range of LDPE-rich blends and miscible in the PP-rich range. The different methods of data analyses, including predictions of theoretical models, support these observations.

The asymmetric nature of miscibility with regard to composition was noted in the experimental results and supported by theories. These explanations are in agreement with theoretical predictions of Frederickson and co-workers on the miscibility of polyolefin blends [29-31]. In addition, the high Mw LDPE/high Mw PP pair is more miscible than the low Mw LDPE/high PP pair. Hence, matching the conformations of PP and LDPE and matching the Mw of LDPE and $\mathrm{PP}$ is a key to the melt miscibility of PP/LDPE blends. 


\section{ACKNOWLEDGEMENT}

The authors are grateful to King Fahd University of Petroleum \& Minerals, Saudi Arabia for providing the fund for this research work through project No SABIC/2005/23.

\section{REFERENCES}

[1] Mickael, C.; Christian, C.; Frederic, P. Experimental and Theoretical Description of Low Frequency Viscoelastic Behaviour in Immiscible Polymer Blends. Polymer, 2010, 45, 4095-4104.

[2] Shanks, R.A.; Li, J.; Yu, L. Polypropylene-Polyethylene Blend Morphology Controlled by Time-Temperature-Miscibility. Polymer, 2000, 41, 2133-2139.

[3] Ali, Z.I.; Youssef, H.A.; Said, H.M.; Saleh, H.H. Thermal Stability of LDPE, iPP and their Blends. Thermochimica Acta, 2005, 438, 70-75.

[4] Dhoble, A.; Kulshreshtha, B.; Ramaswami, S.; Zumbrunnen, D.A. Mechanical Properties of PP-LDPE Blends with Novel Morphologies Produced with a Continuous Chaotic Advection Blender. Polymer, 2005, 46, 2244-2256.

[5] Li, J.; Shanks, R.A.; Long, Y. Miscibility and Crystallisation of Polypropylene-Linear Low Density Polyethylene Blends. Polymer, 2001, 42, 1941-1951.

[6] Brydson, J.A. Plastic Materials, $3^{\text {rd }}$ Edition, Newnes Butterworths, London (1975).

[7] Li, J.; Shanks, R.A.; Olley, R.H.; Greenway, G.R. Miscibility and Isothermal Crystallisation of Polypropylene in Polyethylene Melts. Polymer, 2001, 42, 7685-7694.

[8] Dumoulin, M.M. et al., "Chapter 7 Melt Rheology and Morphology of Linear Low Density Polyethylene/Polypropylene Blends", in Two-Phase Polymer Systems, Utracki, L.A (Ed), Hanser, Munich, pp.185-212 (1991)

[9] Kukaleva, N.; Cser, F.; Jollands, M.; Kosior, E. Comparison of Structure and Properties of Conventional and "High-Crystallinity" Isotactic Polypropylenes and their Blends with MetalloceneCatalyzed Linear Low-Density Polyethylene. I. Relationships between Rheological Behavior and Thermal and Physical Properties. J. Appl. Polym. Sci., 2000, 77, 1591-1599.

[10] Li, J.; Shanks, R.A.; Long, Y. Miscibility and Crystallization of Metallocene Polyethylene Blends with Polypropylene. J. Appl. Polym. Sci., 2003, 87, 1179-1189.

[11] Avalos, F.; Lopez-Manchado, M.A.; Arroyo, M. Crystallization Kinetics of Polypropylene: 1. Effect of Small Additions of LowDensity Polyethylene. Polymer, 1996, 37, 5681-5688.

[12] Hill, M.J.; Puig, C.C. Liquid-Liquid Phase Separation in Blends of a Linear Low-Density Polyethylene with a Low-Density Polyethylene. J. Appl. Polym. Sci., 1997, 65, 1921-1931.

[13] Hussein, I.A.; Hameed, T. Influence of Branching Characteristics on Thermal and Mechanical Properties of Ziegler-Natta and Metallocene Hexene Linear Low-Density Polyethylene Blends with Low-Density Polyethylene. J. Appl. Polym. Sci., 2005, 97, 24882498.

[14] Lu, J.; Sue, H.J. Morphology and Mechanical Properties of Blown Film of LDPE/LLDPE Blend. J. Polym. Sci. Polym. Phys. Ed., 2002, 40, 507-518.

[15] Livanovan, M.; Popova, E.S.; Ledneva, O.A.; Popova, A. Properties and Phase Structure of the Poly(propylene)-Low-Density Poly(ethylene) Blends. Int. J. of Polymeric Materials, 2000, 47, 279-291.
[16] Anna, U.; Anton, M.; Jaroslav, L. DSC Analysis of PolypropyleneLow Density Polyethylene Blend Fibres. Fibres \& Textiles in Eastern Europe, 2005, 5, 129-132.

[17] Dong, L.; Olley, R.H.; Bassett, D.C. On Morphology and the Competition between Crystallization and Phase Separation in Polypropylene-Polyethylene Blends. J. Mat. Sci., 1998, 33, 4043-4048.

[18] Strapasson, R.; Amico, S.C.; Pereira, M.F.R.; Sydenstricker, T.H.D. Tensile and Impact Behavior Polypropylene/Low Density Polyethylene Blends. Polymer Testing, 2005, 25, 468-473.

[19] Teh, J.W.; Rudin, A. Properties and Morphology of Polystyrene and Linear Low Density Polyethylene Polyblend and Polyalloy. Polym. Eng. Sci., 1991, 31, 1033-1042.

[20] Li, J.; Shanks, R.A.; Long, Y. Mechanical Properties and Morphology of Polyethylene-Bolypropylene Blends with Controlled Thermal History. J. Appl. Polym. Sci., 2000, 76, 1151-1164.

[21] Hameed, T.; Hussein, I.A. Rheological Study of the Influence of $\mathrm{M}_{\mathrm{W}}$ and Comonomer Type on the Miscibility of m-LLDPE and LDPE Blends" Polymer, 2002, 43, 6911-6929.

[22] Hussein, I.A.; Ho, K.; Goyal, S.K.; Karbashewski, E.; Williams, M.C. Thermomechanical Degradation in the Preparation of Polyethylene Blends. Polym. Deg. Stability, 2000, 68, 381-392.

[23] Hussein, I.A. Implications of Melt Miscibility on Thermal and Mechanical Properties of Metallocene LLDPE Blends with HDPE: Influence of Comonomer Type. Polymer International, 2005, 54, 1330-1336.

[24] Hussein, I.A.; Hameed, T.; Sharkh, B.F.A.; Mezghani, K. Miscibility of Hexene-LLDPE and LDPE Blends: Influence of Branch Content and Composition Distribution. Polymer, 2003, 44, 4665-4672.

[25] Scholz, P.; Froelich, D.; Muller, R. Viscoelastic Properties and Morphology of Two Phase Polypropylene/Polyamide 6 Blends in the Melt. Interpretation of Results with an Emulsion Model. $J$. Rheol., 1989, 33, 481-499.

[26] Kwag, H.; Rana, D.; Cho, K.; Rhee, J.; Woo, T.; Lee, B.H.; Choe, S. Binary Blends of Metallocene Polyethylene with Conventional Polyolefins: Rheological and Morphological Properties. Polym. Eng. \& Sci., 2000, 40, 1672-1681.

[27] Utracki, L.A. Two Phase Polymer Systems, Hanser Publishers, Munich, (1991).

[28] Fang, Y.; Carreau, P.J.; Lafleur, P.G. Thermal and Rheological Properties of mLLDPE/LDPE Blends. Polym. Eng. Sci., 2005, 45, 1254-1264.

[29] Bates, F.S.; Fredrickson, G.H. Conformational Asymmetry and Polymer-Polymer Thermodynamics. Macromolecules, 1994, 27, 1065-1067.

[30] Fredrickson, G.H.; Liu, A.J. Design of Miscible Polyolefin Copolymer Blends. J. Polym. Sci. Part B: Polym. Phys., 1995, 33, 1203-1212.

[31] Fredrickson, G.H.; Liu, A.J.; Bates, F.S. Entropic Corrections to the Flory-Huggins Theory of Polymer Blends: Architectural and Conformational Effects. Macromolecules, 1994, 27, 2503-2511.

[32] Hameed, T.; Hussein, I.A. Effect of Short Chain Branching of LDPE on its Miscibility with Linear HDPE. Macromol. Mater. Eng., 2004, 289, 198-203.

[33] Hussein, I.A. Influence of Composition Distribution and Branch Content on the Miscibility of m-LLDPE and HDPE Blends. Macromolecules, 2003, 36, 2024-2031, 2029, Erratum: 36(12): 4667.

[34] Hussein, I.A.; Williams, M.C. Rheological Study of the Influence of Branch Content on the Miscibility of Octene m-LLDPE and ZNLLDPE in LDPE. Polym. Eng. Sci., 2004, 44, 660-672. 